\title{
Year of study as predictor of loneliness among students of University of Gondar
}

\author{
Baye Dagnew $^{1 *}$ and Henok Dagne ${ }^{2}$
}

\begin{abstract}
Objectives: Loneliness is individual's subjective sense of lacking familial or social contact to the degree that they wanted. It is responsible for reduced quality of life. The aim of this study was to determine loneliness and its association with year of study among University of Gondar students, 2018/19. Cross-sectional study design was used on 404 Medical and Health Sciences students selected by systematic random sampling. UCLA-R loneliness score was used. A person with a mean value of 42 and above was considered as lonely. After data were collected by self-administered questionnaire, Epi-Data was used for data entry and exported to SPSS version 20.1 for analysis. Variables with p-value of 0.05 and lower were treated as significant factors in multivariable logistic regression.

Results: Prevalence of loneliness was $49.5 \%$ (95\% Cl 44.6-54.4\%). Year of study was significantly associated with loneliness $[A O R=2.47,95 \% \mathrm{Cl}(1.65-3.70)]$. First-year students were having 2.47 odds of loneliness as compared to second year and above students. Loneliness prevalence was higher in the current study. This must get the attention of higher education institutions, the government and all concerned stakeholders in the education sector to design strategy on preventing and treating loneliness.
\end{abstract}

Keywords: Loneliness, Student, Ethiopia

\section{Introduction}

Ability of a person for close connection with other people is one of the most important settings of a healthy personality. Loneliness is individual's personal, subjective sense of lacking social or familial contact to the extent that they wanted [1]. Loneliness affects many physiological processes mainly due to hypothalamic-pituitary-adrenal axis disturbances leading to poor daily performances by inducing sleep in individuals [2]. It affects a person in his all lifespan more likely to occur under circumstances like prolonged absence from home or loss of a significantother [3]. In Ankara University students $60.2 \%$ of students experienced loneliness which was associated with the need for economic support, social interaction and romantic relationship [4]. A study from Maragheh University students indicated prevalence of moderate and severe loneliness as $50.5 \%$ and $31.6 \%$, respectively where

\footnotetext{
*Correspondence: bayedagnew7@gmail.com

${ }^{1}$ Department of Human Physiology, School of Medicine, University of Gondar, P.O. Box 196, Gondar, Ethiopia

Full list of author information is available at the end of the article
}

sex was predictor [5]. Loneliness varies in different settings. About $10.5 \%$ loneliness prevalence was seen in general population of Western Mid-Germany which was higher in females and without partner [6]. Loneliness is predicted by lower family wealth, living in a low or lower middle-income country, low organized religious activity. Lonely students self-reported poor subjective health status, sleeping problems, short sleep duration and tobacco use [7]. Male students had higher levels of Loneliness than females as seen in Anadolu University [8]. The transition from high school to University often causes much stress for most students. In the new University environment, students often face various interpersonal, social, and academic demands, each of which could potentially create stressful situations for most of them which can lead to specific problems in adjustment [9]. Being bound in a romantic relationship is protective in a study done in China, Thai international students and Turkey [10, 11]. Number of semesters was significantly associated with loneliness with lower loneliness in those staying for longer semesters in university [5, 8]. Social isolation is found to be correlated with loneliness that ended up 
with depression among adults as indicated by a study done in London [12]. Quality of life is affected negatively in persons with loneliness [13] pushing adolescents to use life-threatening substances such as Marijuana [14]. Loneliness is responsible for most depressive symptoms [8] and may lead to cognitive impairment [15]. A study in China revealed, loneliness is not only the cause for the poor quality of life but also increases mortality [16]. Loneliness is significantly associated with divorced status, social support and psychological wellbeing [17]. Individuals with loneliness had reduced out of home physical activities [18]. Mental disturbances and other unhealthy states are common in lonely individuals [19]. Freshman students had problems to adjust themselves into new environment as evidenced in University students at Dila, Ethiopia [20]. Cultural backgrounds affect loneliness which may increase loneliness in some and decreases in others [21]. Increased recognition of loneliness as a risk factor for adverse psychological and physical health outcomes has elevated interest in interventions to reduce chronic loneliness [22]. As many scholars agreed, loneliness is one of the major predisposing factors for disturbed quality of life and poor productivity. As far as our knowledge is concerned such kind of study was not conducted in Ethiopia. Because of this, the investigators had been interested in conducting this research. After completion, this might help to add additional information besides the existing literature to the scientific community. The study population will be benefited from the study findings since the results will help the institutions to design interventional strategies for loneliness and related issues. The major objective of this study was assessing loneliness and determining if loneliness is predicted by year of study among University students, University of Gondar, 2018/19.

\section{Main text \\ Methods}

\section{Study area and period}

The study was conducted at University of Gondar, Ethiopia. The University of Gondar has been dedicated to educating students for more than 64 years and serving the community by delivering clinical services in its comprehensive specialized teaching hospital. The study was conducted from Oct 01 to Nov 30, 2018.

Study design: Institution-based cross-sectional study design was employed.

\section{Source population}

All regular students of University of Gondar engaged in learning process in 2018/19. A total of 2358 regular undergraduate students were found in the College of Medicine and Health Sciences.

\section{Study population}

Regular undergraduate Medical and Health Science students of University of Gondar who were engaged in the learning process in the academic calendar of 2018/19 those present at the time of data collection period.

\section{Eligibility criteria}

Inclusion criteria: All regular undergraduate 1st year to graduating class students of University of Gondar College of Medicine and Health Science were included.

Exclusion criteria: students with a severe illness that limits them to fill questions were excluded.

\section{Sample size determination}

The sample size ( $\mathrm{n}$ ) was calculated by using a single population proportion formula by using assumptions; magnitude of loneliness (p) among students in University of Gondar $=50 \%$ (since there was no previous study in Ethiopia, we preferred to use maximum sample size), 95\% level of confidence and 5\% margin of error (d).

$$
\begin{aligned}
\boldsymbol{n} & =\frac{\left(\boldsymbol{z}_{\frac{a}{2}}\right)^{2} \times \boldsymbol{p} \times(1-\boldsymbol{p})}{\boldsymbol{d}^{2}} \\
& =\frac{(1.96)^{2} \times 0.5 \times(1-0.5)}{(0.05)^{2}}=384
\end{aligned}
$$

By adding 5\% (expected non-response rate), the minimum calculated sample was 404 .

\section{Variables of the study}

Dependent variable: Loneliness (Yes/No).

Independent variables: Age, sex, residence before coming to University, marital status, lifestyle (Khat chewing, cigarette smoking), health status, romantic love engagement, year of study and monthly pocket income, current disease status.

\section{Operational definitions}

Loneliness: A person with a mean score of 42 and above out of 80 total standard loneliness score was regarded as having loneliness.

Current disease status: If a student is faced with any sort of disease in the past 1 month from data collection period, he/she is referred to having current disease.

Year of study: The education level of students in the University of Gondar during data collection.

\section{Data collection instrument and procedure}

The structured pretested self-administered questionnaire was used. Revised University of California Los Angeles Loneliness scale (UCLA-R) was used to collect data about subjective feelings of loneliness [23]. A UCLA-R scale 
has 20-item questions with four alternatives $($ Never $=1$, rarely $=2$, Sometimes $=3$, and Often $=4$ ) ranging from 20 (lowest score) to 80 (highest score). First, the adapted questionnaire was prepared in English and translated to Amharic and then, translated back to English by another person to check its consistency and wording. The cutoff point for describing loneliness was calculated by the mean and the score above the mean value was indicative of loneliness. Two supervisors participated in the data collection.

\section{Data quality management/control}

One day training about the ethical issues, the purpose of the study and data collection techniques were given for supervisors. Pretest was performed on 40 students outside of the study area. During data collection, close supervision, spot-checking and reviewing the completed questionnaire were done by the supervisors and principal investigator on daily basis. Data clean up and crosschecking was done before analysis. Cronbach's alpha was done with the result of 0.78 which is acceptable [24].

\section{Data processing and analysis}

Data were edited, coded and entered into epidemiological data (EPI-DATA) version 3.1 and exported to Statistical package for Social Sciences (SPSS) version 20 for analysis. Descriptive statistics were presented in frequency tables with percentage. Students who scored above a mean value (42 and above) were considered as facing loneliness. The bivariable analysis was done for loneliness and independent variables to check for crude association. Variables with a p-value of $<0.2$ in bivariable analysis were candidates and entered to multivariate logistic regression analysis to identify the independent determinants of loneliness. Both Crude Odds Ratio (COR) and the Adjusted Odds Ratio (AOR) with a corresponding 95\% confidence interval (CI) were computed to show the strength of association. Hosmer and Lemeshow goodness of fit test was checked ( $\mathrm{p}$-value $>0.05$ ). Variables with $\mathrm{p}$-value of $<0.05$ in the multivariate logistic regression analysis were taken as statistically significant.

\section{Result}

\section{Description of study participants}

A total of 404 students participated with $100 \%$ response rate. Of these, 242 (59.9\%) were males and 238 (58.9\%) were below 21 years. 127 (31.4\%) students were actively engaged in romantic relationship. Only $3.2 \%$ and $3 \%$ of students were currently chewing chat and smoke cigarette respectively (Table 1).

\section{The magnitude of loneliness among study participants}

From 404, participants 200 (49.5\%) students had a score above mean fore loneliness indicating these had loneliness. Within group, females were lonelier than males but intergroup comparison indicated more males had loneliness. Those who had not engaged in a romantic relationship were more lonely (52\%) as compared to those who were not engaged. The magnitude of loneliness was higher in those rural residents before coming to the university, current khat chewers and cigarette smokers and students with the age group of 21 years and above (Table 2).

\section{Factors associated with Loneliness}

All independent variables were tested for crude association with loneliness by binary logistic regression. Of the tested variables; Sex, Active engagement in a romantic relationship and year of study had a p-value of $<0.2$ and hence entered to multivariable logistic regression with a backward Likelihood ratio (LR) to find out significantly associated factors of loneliness. In multivariable logistic regression, only year of study was significantly associated ( $p$-value $=0.00$ ). After controlling other variables constant, first-year students were 2.47 times more likely to develop loneliness than second year and above $[\mathrm{AOR}=2.47,95 \% \mathrm{CI}(1.651-3.701)]$ (Table 2$)$.

\section{Discussion}

Findings of the current study revealed the magnitude of loneliness among University of Gondar students being 49.5\% [95\% CI 44.6-54.4\%] which is a major public health problem with females more affected than males in proportion. This is lower than a report in Turkey University students which disclosed $60.2 \%$ loneliness [4]. In contrary, the result of this study showed a higher prevalence of loneliness as compared to a study in Mid-Germany that reported a $10.5 \%$ [6] and $10.2 \%$ (meta-analysis study) prevalence of loneliness [25]. This difference could be associated with the nature of study participants, sample size and sociocultural differences. No more articles were found about the magnitude of loneliness that limited us to compare our study findings.

As indicated in different studies, there were different factors contributing to loneliness like family residence, romantic relationship (partnership), sex and family wealth (income) [2]. In this study amongst the covariates tested in binary logistic regression, only sex, Active engagement in a romantic relationship and year of study had p-value less than 0.2. Of these variables year of study was significantly associated with loneliness; being first year is highly risky for having loneliness than second year and above students. The association of loneliness among first year (freshman) students could be due to the short 
Table 1 Socio-demographic property of participants, University of Gondar, $2018(n=404)$

\begin{tabular}{|c|c|c|c|}
\hline Study variables & Categories & Frequency $(\mathrm{N})$ & Percentage (\%) \\
\hline \multirow[t]{2}{*}{ Sex } & Male & 242 & 59.9 \\
\hline & Female & 162 & 40.1 \\
\hline \multirow[t]{2}{*}{ Age } & 20 years and lower & 238 & 58.9 \\
\hline & 21 years and above & 166 & 41.1 \\
\hline \multirow[t]{5}{*}{ Religion } & Orthodox & 318 & 78.7 \\
\hline & Muslim & 31 & 7.7 \\
\hline & Protestant & 45 & 11.1 \\
\hline & Catholic & 8 & 2.0 \\
\hline & Others & 2 & 0.5 \\
\hline \multirow[t]{2}{*}{ Engaged in romantic love } & Yes & 127 & 31.4 \\
\hline & No & 277 & 68.6 \\
\hline \multirow[t]{2}{*}{ Residence before coming to university } & Urban & 246 & 60.9 \\
\hline & Rural & 158 & 39.1 \\
\hline \multirow[t]{2}{*}{ Current Khat chewing } & Yes & 13 & 3.2 \\
\hline & No & 391 & 96.8 \\
\hline \multirow[t]{2}{*}{ Current cigarette smoking } & Yes & 12 & 3.0 \\
\hline & No & 392 & 97.0 \\
\hline \multirow[t]{2}{*}{ Current disease status } & Yes & 199 & 49.3 \\
\hline & No & 205 & 50.7 \\
\hline \multirow[t]{4}{*}{ Management of subjective loneliness } & Go to religious places & 251 & 62.1 \\
\hline & Go to recreational places & 60 & 14.9 \\
\hline & Go to sleep & 70 & 17.3 \\
\hline & Watching TV/Film & 23 & 5.7 \\
\hline \multirow[t]{2}{*}{ Year of study } & First year & 226 & 55.9 \\
\hline & Second year \& above & 178 & 44.1 \\
\hline \multirow[t]{4}{*}{ Monthly pocket money } & $50-400$ & 111 & 27.5 \\
\hline & $401-500$ & 106 & 26.2 \\
\hline & $501-1000$ & 134 & 33.2 \\
\hline & Above 1000 & 53 & 13.1 \\
\hline \multirow[t]{2}{*}{ Marital status } & Single & 392 & 97.0 \\
\hline & Married & 12 & 3.0 \\
\hline
\end{tabular}

duration of stay in the University to adapt the new environment which is supported by a study done in Washington University that indicated leaving home for college made students susceptible to experience loneliness [26]. Being in a romantic relationship is preventive to loneliness as reported in Germany [27] even though it is not significantly associated in our study. Our study findings indicated a major proportion of students were affected by loneliness which gives insight for University authorities to work on loneliness preventive and therapeutic strategies so as to reduce difficulties of students in the learning environment. This study revealed a higher magnitude of loneliness which is mainly found in first-year students. Being first year is more prone to loneliness. This gives a clue for officials to include coping strategies for loneliness in University students. The investigators would like to recommend researchers to conduct more qualitative studies to find out concrete information on loneliness. Besides this, Universities has to plan on how to put students in a comfortable situation while they are separating from their family. Above all guidance and counseling institutions in Universities has to approach students to prevent and treat loneliness.

\section{Limitation of the study}

This study was undertaken using a standardized tool which helped to compare with previous studies. The generalizability and validity of the study result is good. However, this study was not without limitations. The potential limitations include the nature of the study design which cannot be used to show cause-effect relationship. In addition the self-reported nature of the study tool might result in social desirability bias. 
Table 2 Associated factors of loneliness in multivariable logistic regression among study participants, University of Gondar, $2018(n=404)$

\begin{tabular}{|c|c|c|c|c|c|c|c|}
\hline \multirow[t]{3}{*}{ Variable } & \multirow[t]{3}{*}{ Categories } & \multicolumn{4}{|c|}{ Loneliness status } & \multirow{3}{*}{$\begin{array}{l}\text { COR } \\
\text { OR }(95 \% \mathrm{Cl})\end{array}$} & \multirow{3}{*}{$\begin{array}{l}\text { AOR }(95 \% \mathrm{Cl}) \\
\text { OR }(95 \% \mathrm{Cl})\end{array}$} \\
\hline & & \multicolumn{2}{|c|}{ Lonely } & \multicolumn{2}{|c|}{ Not lonely } & & \\
\hline & & $\mathbf{N}$ & $(\%)$ & $\mathbf{N}$ & $(\%)$ & & \\
\hline \multirow[t]{2}{*}{ Sex } & Male & 113 & 46.7 & 129 & 53.3 & 1 & \\
\hline & Female & 87 & 53.7 & 75 & 46.3 & $1.324(0.89-1.97)$ & $1.3(0.87-1.98)$ \\
\hline \multirow[t]{2}{*}{ Actively engaged in romantic friendship } & Yes & 56 & 44.1 & 71 & 55.9 & 1 & \\
\hline & No & 144 & 52.0 & 133 & 48.0 & $1.37(0.90-2.09)$ & $1.3(0.85-2.02)$ \\
\hline \multirow[t]{2}{*}{ Residence before coming to university } & Urban & 117 & 47.6 & 129 & 52.4 & 1 & \\
\hline & Rural & 83 & 52.5 & 75 & 47.5 & $1.22(0.82-1.82)$ & \\
\hline \multirow[t]{2}{*}{ Current khat chewing } & Yes & 7 & 53.8 & 6 & 46.2 & $1.19(0.39-3.63)$ & \\
\hline & No & 193 & 49.4 & 198 & 50.6 & 1 & \\
\hline \multirow[t]{2}{*}{ Current cigarette smoking } & Yes & 6 & 50 & 6 & 50.0 & $1.02(0.32-3.22)$ & \\
\hline & No & 194 & 49.5 & 198 & 50.5 & 1 & \\
\hline \multirow[t]{2}{*}{ Current disease status } & Yes & 102 & 51.3 & 97 & 48.7 & $1.15(0.77-1.69)$ & \\
\hline & No & 98 & 47.8 & 107 & 52.2 & 1 & \\
\hline \multirow[t]{2}{*}{ Age in years } & 20 \& lower & 120 & 50.4 & 118 & 49.6 & $1.09(0.74-1.63)$ & \\
\hline & $21 \&$ above & 80 & 48.2 & 86 & 51.8 & 1 & \\
\hline \multirow[t]{2}{*}{ Year of study } & First & 134 & 59.3 & 92 & 40.7 & $2.47(1.67-3.7)$ & $2.47(1.65-3.70) a$ \\
\hline & 2nd \& above & 66 & 37.1 & 112 & 62.9 & 1 & 1 \\
\hline \multirow[t]{4}{*}{ Monthly pocket money in ETB } & $50-400$ & 53 & 47.7 & 58 & 52.3 & $0.82(0.42-1.5)$ & \\
\hline & $401-500$ & 46 & 43.4 & 60 & 56.6 & $0.68(0.35-1.33)$ & \\
\hline & $501-1000$ & 73 & 54.5 & 61 & 45.5 & $1.07(0.56-2.02)$ & \\
\hline & $>1000$ & 28 & 52.8 & 25 & 47.2 & 1 & \\
\hline \multirow[t]{2}{*}{ Marital status } & Single & 192 & 49.0 & 200 & 51.0 & $0.48(0.14-1.62)$ & \\
\hline & Married & 8 & 66.7 & 4 & 33.3 & 1 & \\
\hline
\end{tabular}

Cl: confidence interval; COR: Crude odds ratio; AOR: Adjusted odds ratio; ${ }^{2}$ Indicates significantly associated variable with loneliness in multivariable analysis

\section{Abbreviations}

AOR: adjusted odds ratio; Cl: confidence interval; COR: crude odds ratio; Epi-Data: epidemiological data; SPSS: Statistical package for social sciences; UCLA-R: Revised University of California Loneliness Assessment scale.

\section{Authors' contributions}

$B D$ and $H D$ involved in proposal development, participated in data collection, statistical analysis, and manuscript write-up. All authors read and approved the final manuscript.

\section{Author details}

1 Department of Human Physiology, School of Medicine, University of Gondar, P.O. Box 196, Gondar, Ethiopia. ${ }^{2}$ Department of Environmental and Occupational Health and Safety, Institute of Public Health, University of Gondar, P.O. Box 196, Gondar, Ethiopia.

\section{Acknowledgements}

We would like to thank our study participants and data collectors for their collaboration.

\section{Competing interests}

The authors declare that they have no competing interests.

\section{Availability of data and materials}

The dataset in the current study is available from the corresponding author upon request.

\section{Consent for publication}

Not applicable.
Ethics approval and consent to participate

Ethical approval was obtained from the Ethical committee of Department of Environmental and Occupational Health and Safety, University of Gondar with ethical approval number EOHS/814/2011. Written consent was taken from each study participants.

\section{Funding}

No funding was obtained for this work.

\section{Publisher's Note}

Springer Nature remains neutral with regard to jurisdictional claims in published maps and institutional affiliations.

Received: 5 March 2019 Accepted: 22 April 2019

Published online: 29 April 2019

\section{References}

1. Daniel K. Loneliness and depression among university students in Kenya. Glob J Hum Soc Sci Arts Humanit. 2013;13(4):1-9.

2. Zilioli S, Slatcher RB, Chi P, Li X, Zhao J, Zhao G, et al. The impact of daily and trait loneliness on diurnal cortisol and sleep among children affected by parental HIV/AIDS. Psychoneuroendocrinology. 2017;75:64-71

3. Sawir E, Marginson S, Deumert A, Nyland C, Ramia G. Loneliness and international students: an Australian study. J Stud Int Educ. 2008;12(2):148-80 
4. Özdemir U, Tuncay T. Correlates of loneliness among university students. Child Adolesc Psychiatry Ment Health. 2008;2:1-6.

5. Parvan R, Karimi F, Safiri S, Mahdavi N. Prevalence of loneliness and associated factors among Iranian College students during 2015. J Arch Mil Med. 2017;5(1):e42356.

6. Beutel ME, Klein EM, Brähler E, Reiner I, Jünger C, Michal M, et al. Loneliness in the general population: prevalence, determinants and relations to mental health. BMC Psychiatry. 2017;17:97.

7. Peltzer K, Pengpid S. Loneliness: Its correlates and associations with health risk behaviours among university students in 25 countries. J Psychol Africa. 2017;27(3):247-55.

8. Ceyhan E, Ceyhan AA. Loneliness and depression. Educ Sci. 2011;36(160):17-9.

9. Sadoughi M. Relationship between social support and loneliness and academic adjustment among university students. Int J Acad Res Psychol. 2016;3(2):1-8

10. Lin Y, Kingminghae W. Social support and loneliness of Chinese international students in Thailand. J Popul Soc Stud. 2014;22(2):141-57.

11. Ari R, Konya C, John S. An investigation of social skills and loneliness. 2005;33(1):19-32.

12. Matthews T, Danese A, Wertz J, Odgers CL, Ambler A, Moffitt TE, et al. Social isolation, loneliness and depression in young adulthood: a behavioural genetic analysis. Soc Psychiatry Psychiatr Epidemiol. 2016;51(3):339-48.

13. Świtaj P, Grygiel P, Chrostek A, Wciórka J, Anczewska M. Investigating the roles of loneliness and clinician- and self-rated depressive symptoms in predicting the subjective quality of life among people with psychosis. Soc Psychiatry Psychiatr Epidemiol. 2018;53(2):183-93.

14. Stickley A, Koyanagi A, Koposov R, Schwab-Stone M, Ruchkin V. Loneliness and health risk behaviours among Russian and U.S. adolescents: a cross-sectional study. BMC Public Health. 2014;14(1):1-12.

15. Zhong BL, Chen SL, Tu X, Conwell Y. Loneliness and cognitive function in older adults: findings from the chinese longitudinal healthy longevity survey. Journals Gerontol - Ser B Psychol Sci Soc Sci. 2017;72(1):120-8.

16. Gerst-Emerson K, Jayawardhana J. Loneliness as a public health issue: the impact of loneliness on health care utilization among older adults. Am J Public Health. 2015;105(5):1013-9.
17. Stickley A, Koyanagi A, Roberts B, Richardson E, Abbott P, Tumanov S, et al. Loneliness: its correlates and association with health behaviours and outcomes in nine countries of the former Soviet Union. PLOS ONE. 2013;8(7):e67978.

18. Queen TL, Stawski RS, Ryan LH, Smith J. Loneliness in a day: Activity engagement, time alone, and experienced emotions. Psychol Aging. 2014;29(2):297-305.

19. Richard A, Rohrmann S, Vandeleur CL, Schmid M, Eichholzer M. Loneliness is adversely associated with physical and mental health and lifestyle factors: results from a Swiss national survey. PLOS ONE. 2017;12:e0181442.

20. Belay Ababu G, Belete Yigzaw A, Dinku Besene Y, Getinet Alemu W. Prevalence of adjustment problem and its predictors among first-year undergraduate students in Ethiopian University: a cross-sectional institution based study. Psychiatry J. 2018;2018:1-7.

21. Sønderby LC. Loneliness: an integrative approach. J Integr Soc Sci. 2013;3(1):1-29.

22. Cacioppo S, Grippo AJ, London S, Goossens L, John T, Development A. Loneliness: clinical import and interventions. Perspect Psychol Sci. 2015;10(2):238-49.

23. Russell D. Ucla loneliness scale version 3 (description of measure). J Pers Soc Psychol. 1996;39:3-4.

24. George D, 2003. SPSS for windows step by step: a simple study guide and reference, 17.0 update, 10/e. Pearson Education India.

25. Menec VH, Newall NE, Mackenzie CS, Shooshtari S, Nowicki S. Examining individual and geographic factors associated with social isolation and loneliness using Canadian Longitudinal Study on Aging ( CLSA) data. PLOS ONE. 2019;14(2):1-18.

26. English T, Davis J, Gross JJ. Homesickness and adjustment across the first year of college: a longitudinal study. Anal Chem. 2017;27(1):1-5.

27. Diehl K, Jansen C, Ishchanova K, Hilger-Kolb J. Loneliness at universities: determinants of emotional and social loneliness among students. Int J Environ Res Public Health. 2018;15(9):1865.
Ready to submit your research? Choose BMC and benefit from:

- fast, convenient online submission

- thorough peer review by experienced researchers in your field

- rapid publication on acceptance

- support for research data, including large and complex data types

- gold Open Access which fosters wider collaboration and increased citations

- maximum visibility for your research: over $100 \mathrm{M}$ website views per year

At $\mathrm{BMC}$, research is always in progress.

Learn more biomedcentral.com/submissions 